\title{
Evaluation of high performance liquid chromatography for routine estimation of haemoglobins $A_{2}$ and $F$
}

\author{
G B Tan, T C Aw, R A Dunstan, S H Lee
}

\begin{abstract}
Aims-To compare high performance liquid chromatography (HPLC) with conventional methods for the estimation of blood haemoglobin $A_{2}\left(H_{b} A_{2}\right)$ and haemoglobin $F$ (HbF) concentrations in routine thalassaemia screening.

Methods-An HPLC system (the VARIANT Hemoglobin Testing System) was tested for precision and reproducibility in the measurement of $\mathrm{HbA}_{2}$ and $\mathrm{HbF}$, and reference ranges were obtained for a local healthy adult population. HPLC was compared with column anion exchange chromatography for $\mathrm{HbA}_{2}$ measurement, and radial immunodiffusion, or alkaline denaturation for $\mathrm{HbF}$ measurement. The reliability of $\mathbf{H b A}_{2}$ measurement by HPLC for the detection of $\beta$ thalassaemia and HbE was assessed in 200 consecutive samples for routine thalassaemia screening.
\end{abstract}

Results-HPLC was rapid, technically easy, and gave good precision and reproducibility. In all comparisons linear regression analysis showed good correlation between $\mathrm{HbA}_{2}$ or $\mathrm{HbF}$ concentrations determined by HPLC and by the respective conventional methods. All $\beta$ thalassaemia or haemoglobin $E$ carriers presumptively identified by conventional methods in 200 consecutive samples were detected by $\mathrm{HbA}_{2}$ measurement using HPLC, without any false positive or false negative results.

Conclusions-The measurement of $\mathrm{HbA}_{2}$ and HbF by HPLC is rapid, reproducible, and precise. It is as reliable as column chromatography for the measurement of $\mathrm{HbA}_{2}$ and radial immunodiffusion or alkaline denaturation for the measurement of HbF. HPLC may be an appropriate method for rapid screening in population surveys for $\beta$ thalassaemia and HbE carriers.

(f Clin Pathol 1993;46:852-856)

Useful variables in the routine laboratory diagnosis of thalassaemia include the haemoglobin concentration, erythrocyte indices and morphology, haemoglobin electrophoresis, haemoglobin $\mathrm{A}_{2}\left(\mathrm{HbA}_{2}\right)$ and haemoglobin $\mathrm{F}$ $(\mathrm{HbF})$ estimation, and the detection of erythrocyte haemoglobin $\mathrm{H}(\mathrm{HbH})$ inclusions. ${ }^{1-4}$ These data may need to be supplemented with clinical information such as the age and family history of the patient, and tests to exclude iron deficiency. ${ }^{12}$ A practical means of diagnosis of $\beta$ thalassaemia is by detection of an increased concentration of $\mathrm{HbA}_{2}{ }^{4}$ Indeed, successful prevention programmes for $\beta$ thalassaemia in Greece and Italy have relied on screening by erythrocyte indices and $\mathrm{HbA}_{2}$ concentrations. ${ }^{5}$ Haemoglobin E $(\mathrm{HbE})$, which co-migrates with $\mathrm{HbA}_{2}$ in conventional electrophoretic or chromatographic methods, ${ }^{1-3}$ is another haemoglobin disorder with a high incidence in many parts of South East Asia. ${ }^{67}$ An accurate and simple method for the measurement of $\mathrm{HbA}_{2}$ and $\mathrm{HbF}$ concentrations could be a useful tool in screening programmes for $\beta$ thalassaemia and $\mathrm{HbE}$.

Although cellulose acetate electrophoresis is the best routine method for separating abnormal haemoglobins, ${ }^{3}$ chromatographic procedures are also useful for confirmation and quantitation. ${ }^{8}$ Low pressure macro-column chromatography, using a weak cation exchange material, such as $\mathrm{cm}$-cellulose or an anion exchange material, such as DEAEcellulose is most commonly used. ${ }^{9}$ This procedure, however, is labour intensive and time consuming. Microchromatographic techniques decrease the chromatographic time but sacrifice resolution.

High performance liquid chromatography (HPLC) is a sensitive and precise method for detecting abnormal haemoglobins. ${ }^{10}$ It has advantages over conventional chromatographic techniques in terms of its speed and reliability. In recent years it has been applied to separate and quantitate various haemoglobin fractions. ${ }^{11-14}$

\section{Methods}

As normal adult blood concentrations of $\mathrm{HbA}_{2}$ and $\mathrm{HbF}$ may vary with methodology, reference ranges of $\mathrm{HbA}_{2}$ and $\mathrm{HbF}$ were obtained for the VARIANT Hemoglobin Testing System (Bio Rad Laboratories, Hercules, California, USA) in a population of 104 healthy adults. The VARIANT was compared against a column ion exchange method of $\mathrm{HbA}_{2}$ measurement in 200 consecutive samples for routine thalassaemia screening, and against radial immunodiffusion (RID) or alkaline denaturation ${ }^{15} 16$ for $\mathrm{HbF}$ measurement in 147 consecutive samples for routine thalassaemic screening.

Erythrocyte indices were determined using the Technicon $H^{\star} 1$ cell counter (Bayer Diagnostics, Hants, United Kingdom). Haemoglobin electrophoresis in cellulose

Correspondence to:

$S$ H Lee

Accepted for publication 22 April 1993 
acetate at $\mathrm{pH} 8.4$ or citrate agar at $\mathrm{pH} 6.0$ was performed using standard methods. ${ }^{3}$ $\mathrm{HbH}$ inclusions were stained by brilliant cresyl blue as described. ${ }^{3}$

All reagents were provided by the manufacturers, and equipment and reagents were used according to the manufacturers' instructions. The VARIANT is a fully automated cation exchange HPLC system which uses buffers and conditions specifically designed to separate and quantitate $\mathrm{HbA}_{2}$ and $\mathrm{HbF}$. The analyser makes use of two dual piston pumps and a pre-programmed gradient to allow two different sodium phosphate buffers of increasing ionic strength to pass through a column containing spherical cation exchange resin during a 6.5 minute program. Haemolysed samples are kept at a constant $12^{\circ} \mathrm{C}$ (SEM $2^{\circ} \mathrm{C}$ ) in the autosampler chamber until they are automatically injected into the

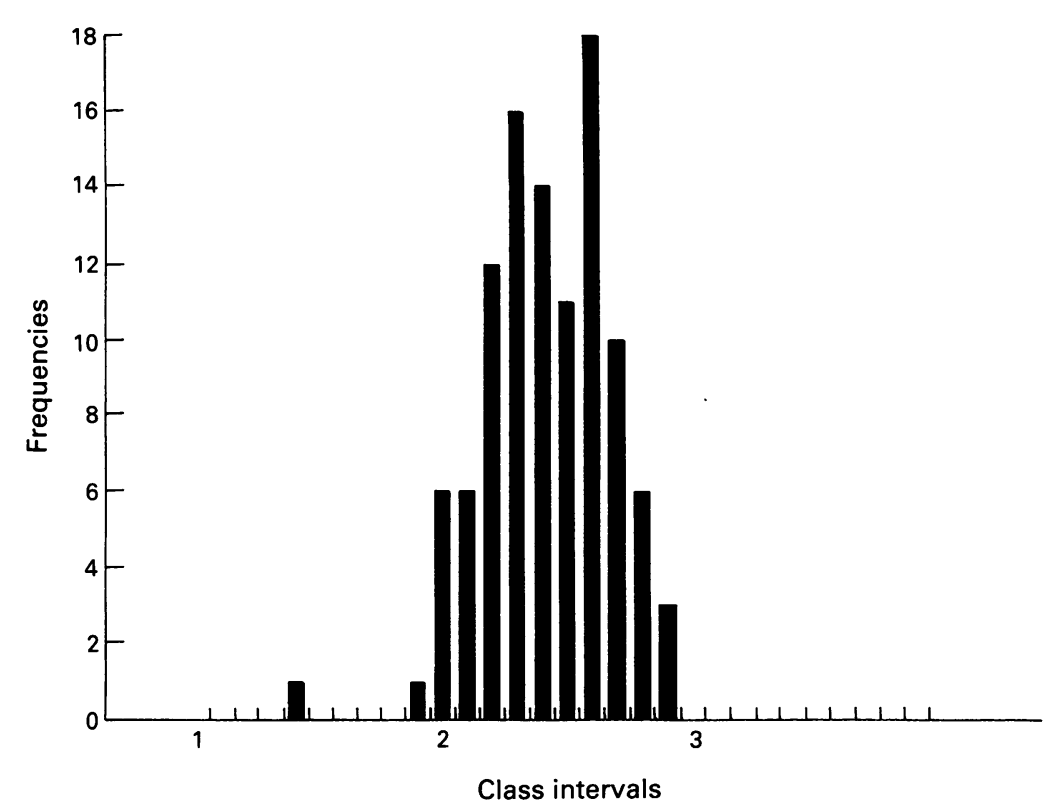

Figure 1 Frequency histogram of the $\mathrm{Hb}_{2}$ concentration in 104 healthy adults.

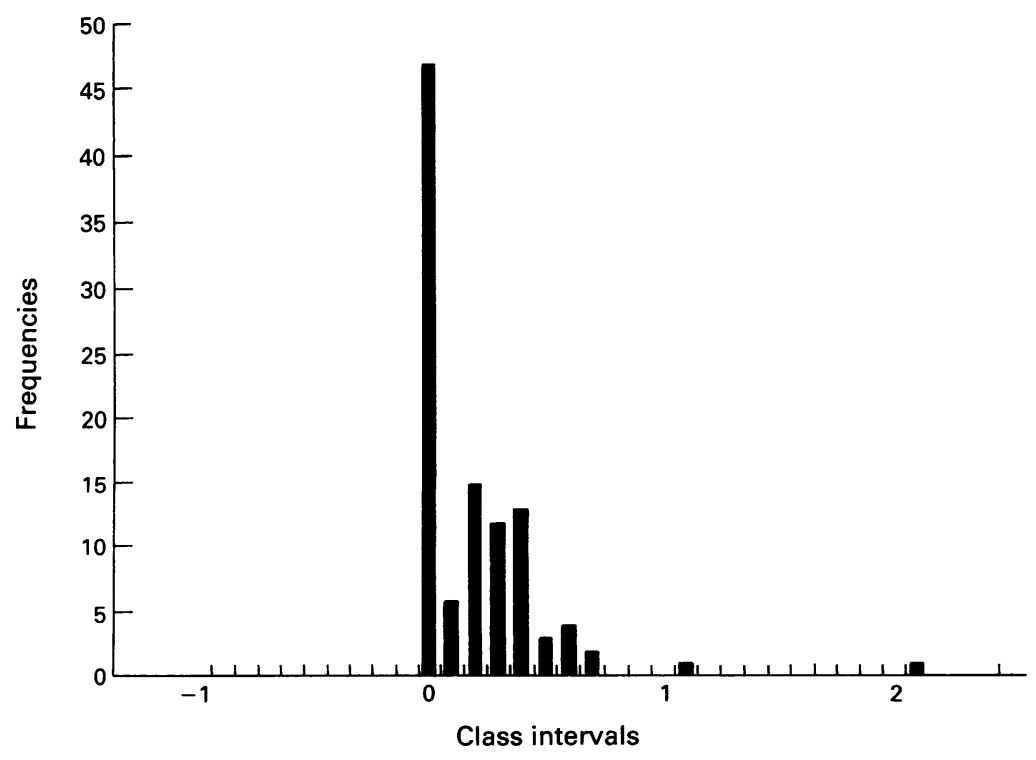

Figure 2 Frequency histogram of the HbF concentration in 104 healthy adults. analysis stream. The optical density of the eluate is determined by spectrophotometry incorporated in the equipment which reads at two wavelengths, $415 \mathrm{~nm}$ and $690 \mathrm{~nm}$. Specific haemoglobin variants consistently elute within certain retention time frames. A built-in microprocessor and integrator analyses test data to produce a retention profile with percentage $\mathrm{HbA}_{2}$ and $\mathrm{HbF}$ values. Each subfraction is presumptively identified based on predefined retention times. The instrument was calibrated with a haemoglobin $\mathrm{A}_{2} / \mathrm{F}$ haemolysate supplied by the manufacturer. Samples were run together with two levels of $\mathrm{A}_{2} / \mathrm{F}$ controls, also supplied by the manufacturer, in each run.

$\mathrm{HbA}_{2}$ was estimated using an anion exchange method, the $\beta$-thal Quik column (Helena Laboratories, Beaumont, Texas, USA). HbF quantitation was carried out by alkaline denaturation using Betke's method $^{1516}$ or by RID, using the HbF Quiplate procedure (Helena Laboratories, Beaumont, Texas, USA). All commercial methods were carried out according to manufacturers' protocols.

Regression analysis was carried out by the method of least squares fit.

\section{Results \\ REFERENCE RANGES FOR HBA ${ }_{2}$ AND HBF \\ CONCENTRATIONS BY HPLC}

Blood samples from healthy blood donors were used to establish the reference range. Subjects with abnormal erythrocyte indices were excluded. The remaining 104 adults (26 women and 78 men aged between 18 to 52 years) had haemoglobin concentrations within the normal range (130-170 g/l for men and 115-155 $\mathrm{g} / 1$ for women). The mean blood $\mathrm{HbA}_{2}$ concentration of these 104 adults was $2 \cdot 4 \%$, with values ranging from 1.4 to $2 \cdot 9$, and a standard deviation (SD) of $0.26 \%$. The $95 \%$ confidence limits were 1.9 to 3.0 (fig 1). The concentrations of blood $\mathrm{HbF}$ ranged from 0.0 to $2 \cdot 1 \%$, with a mean (SD) of $0.2(0.29) \%$. The $95 \%$ confidence limits were 0 to $0.8 \%$ (fig 2 ).

\section{PRECISION STUDIES OF $\mathrm{HBA}_{2}$ AND HBF MEASUREMENT BY HPLC}

Precision studies were performed using two blood samples with normal or raised values of $\mathrm{HbA}_{2}$ or $\mathrm{HbF}$. Each sample was analysed in 10 replicates on three different days. Results (table 1) show low inter- and intra-assay variability for the measurement of normal or raised $\mathrm{HbA}_{2}$ concentrations, and for the measurement of raised $\mathrm{HbF}$ concentrations. An increase in interassay variability was apparent in the measurement of normal $\mathrm{HbF}$ concentrations.

THALASSAEMIA SCREENING

Two hundred consecutive subjects for routine thalassaemia screening were evaluated at the National University Hospital by erythrocyte indices and morphology, haemoglobin electrophoresis in cellulose acetate (pH 8.4), 
Table 1 Precision of $\mathrm{Hb}_{2}$ and $\mathrm{HbF}$ measurement by $\mathrm{HPLC}$

\begin{tabular}{|c|c|c|c|c|c|c|c|}
\hline & \multirow[b]{2}{*}{$N$} & \multicolumn{3}{|l|}{$H b A_{2}$} & \multicolumn{3}{|l|}{$H b F$} \\
\hline & & Mean \% & $S D$ & $C V$ & Mean \% & $S D$ & $C V$ \\
\hline $\begin{array}{c}\text { Sample } 1 \\
\text { Day } 1 \\
\text { Day } 2 \\
\text { Day } 3\end{array}$ & $\begin{array}{l}10 \\
10 \\
10\end{array}$ & $\begin{array}{l}2 \cdot 73 \\
2 \cdot 66 \\
2 \cdot 67\end{array}$ & $\begin{array}{l}0.082 \\
0.052 \\
0.067\end{array}$ & $\begin{array}{l}3.0 \\
1.9 \\
2.5\end{array}$ & $\begin{array}{l}0.43 \\
0.41 \\
0.43\end{array}$ & $\begin{array}{l}0.048 \\
0.032 \\
0.067\end{array}$ & $\begin{array}{r}11 \cdot 2 \\
7 \cdot 7 \\
15 \cdot 7\end{array}$ \\
\hline $\begin{array}{c}\text { Sample } 2 \\
\text { Day } 1 \\
\text { Day } 2 \\
\text { Day } 3\end{array}$ & $\begin{array}{l}10 \\
10 \\
10\end{array}$ & $\begin{array}{l}4 \cdot 07 \\
3 \cdot 92 \\
3 \cdot 78\end{array}$ & $\begin{array}{l}0.082 \\
0.092 \\
0.079\end{array}$ & $\begin{array}{l}2 \cdot 0 \\
2 \cdot 3 \\
2 \cdot 1\end{array}$ & $\begin{array}{l}6.93 \\
6.81 \\
6.71\end{array}$ & $\begin{array}{l}0.150 \\
0.088 \\
0.145\end{array}$ & $\begin{array}{l}2 \cdot 2 \\
1 \cdot 3 \\
2 \cdot 2\end{array}$ \\
\hline
\end{tabular}

Table 2 Cases detected among 200 consecutive subjects screened for thalassaemia

\begin{tabular}{|c|c|c|c|c|}
\hline & $\begin{array}{l}\beta \text {-thalassaemia } \\
\text { trait }\end{array}$ & $\begin{array}{l}\text { a-thalassaemia } \\
\text { trait }\end{array}$ & $\begin{array}{l}\text { HbH } \\
\text { disease }\end{array}$ & $\begin{array}{l}\text { HbE } \\
\text { trait }\end{array}$ \\
\hline $\begin{array}{l}\mathrm{N} \\
\mathrm{Hb}^{*} \\
(\mathrm{~g} / 1) \\
\mathrm{MCV}^{*} \\
(\mathrm{fl}) \\
\mathrm{MCH}^{*} \\
(\mathrm{pg}) \\
\mathrm{MCHC} \\
(\mathrm{g} / \mathrm{l}) \\
\% \mathrm{HbA}_{2}^{*} \\
\% \mathrm{HbF}^{*}\end{array}$ & $\begin{array}{c}39 \\
106 \\
(68-154) \\
64 \cdot 7 \\
(59 \cdot 2-77 \cdot 9) \\
19 \cdot 9 \\
(17 \cdot 5-21 \cdot 7) \\
309 \\
(270-328) \\
4 \cdot 6 \\
(3 \cdot 8-6 \cdot 3) \\
0.9\end{array}$ & $\begin{array}{l}25 \\
108 \\
(74-140) \\
68 \cdot 5 \\
(58 \cdot 1-78 \cdot 7) \\
21 \cdot 1 \\
(16 \cdot 5-23 \cdot 4) \\
310 \\
(271-362) \\
2 \cdot 0 \\
(1 \cdot 4-2 \cdot 6) \\
0 \cdot 4\end{array}$ & $\begin{array}{l}3 \\
93 \\
(84-111) \\
71 \cdot 0 \\
(57 \cdot 2-80 \cdot 1) \\
17 \cdot 7 \\
(16 \cdot 6-18 \cdot 3) \\
256 \\
(235-290) \\
1 \cdot 2 \\
(1 \cdot 1-1 \cdot 4) \\
0 \cdot 5\end{array}$ & $\begin{array}{c}7 \\
111 \\
(80-153) \\
71 \cdot 9 \\
(63 \cdot 3-75 \cdot 8) \\
23 \cdot 4 \\
(19 \cdot 5-26 \cdot 4) \\
324 \\
(308-342) \\
25 \cdot 8 \\
(17 \cdot 3-29 \cdot 9) \\
0.6\end{array}$ \\
\hline
\end{tabular}

$\star=$ mean (range).

$\mathrm{HbA}_{2}$ and $\mathrm{HbF}$ concentrations were determined by HPLC. All subjects tabulated are aged 1 year old and over. Two infants with $a$-thalassaemia trait were excluded from this table.

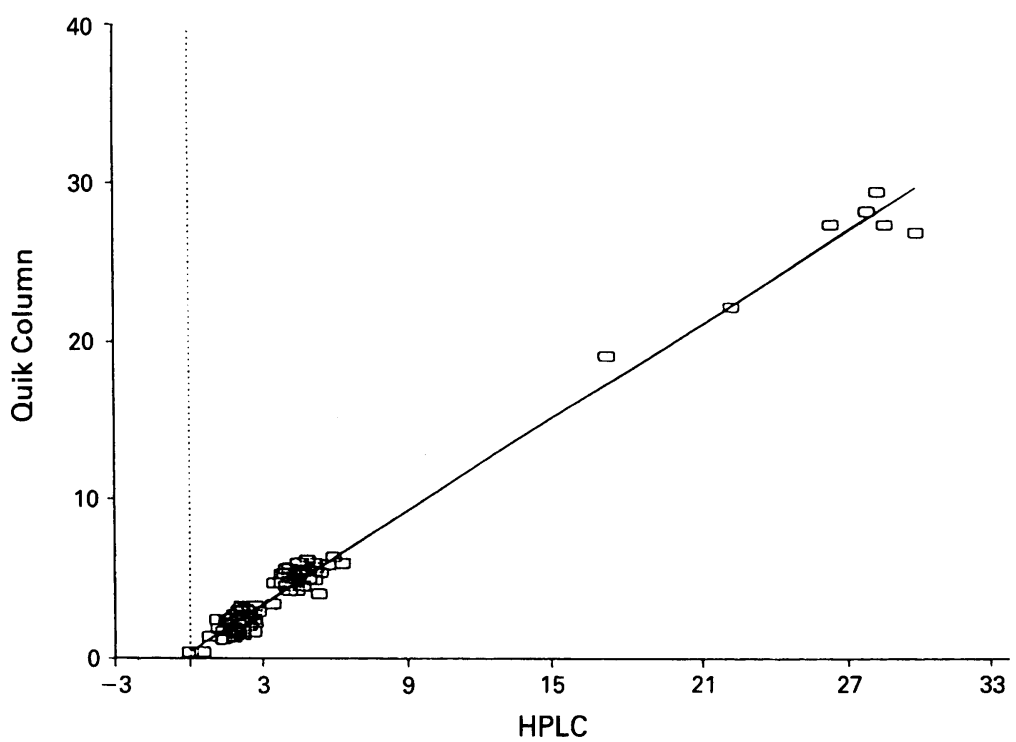

Figure 3 Linear regression plot of $\mathrm{HbA}_{2}$ concentrations measured by the $\beta$-thal Quik Column method against $H b A_{2}$ concentrations measured by HPLC. Correlation coefficient $r=0.99 ; n=200$.

erythrocyte $\mathrm{HbH}$ inclusions, and $\mathrm{HbA}_{2}$ and $\mathrm{HbF}$ concentrations. Subjects came from the routine inpatient and outpatient hospital population, including antenatal clinics. In most subjects with microcytic and hypochromic indices iron deficiency was excluded by serum iron or ferritin estimation. Using this analysis, 39 had $\beta$ thalassaemia trait, $27 a$ thalassaemia trait, and three haemoglobin $\mathrm{H}$ disease (table 2). Of the subjects found to have $\beta$ thalassaemia trait, $\mathrm{HbA}_{2}$ concentrations were raised in all cases, while $\mathrm{HbF}$ values were raised $(\geq 0.8 \%)$ in 18 out of 39 (46\%) cases. Presumptive diagnoses of $a$ thalassaemia trait or $\mathrm{HbH}$ disease were all confirmed by finding erythrocyte $\mathrm{HbH}$ inclusion in very scanty or in large numbers, respectively. The three subjects with $\mathrm{HbH}$ disease had low $\mathrm{HbA}_{2}$ values (range $1 \cdot 1-1 \cdot 4 \%)$. Investigations to exclude $a$ thalassaemia 2 carriers in whom $\mathrm{HbH}$ inclusions may be undetectable, ${ }^{4}$ were not carried out in this study.

Seven samples with apparently high $\mathrm{HbA}_{2}$ concentrations of more than $7 \%$ (range $17 \%-30 \%$ ) were further screened by electrophoresis in citrate agar at $\mathrm{pH} \mathrm{6.0.} \mathrm{None} \mathrm{of}$ these samples showed any additional bands in citrate agar electrophoresis at $\mathrm{pH} 8 \cdot 0$. These results, together with other variables including erythrocyte indices, morphology, and $\mathrm{HbF}$ concentrations (table 2), were consistent with heterozygous $\mathrm{HbE}$ in all seven samples. No other abnormal haemoglobin variants were detected in this study.

COMPARISON OF HPLC WITH OTHER METHODS Quantitation of $\mathrm{HbA}_{2}$ by HPLC was compared with the $\beta$-thal $\mathrm{HbA}_{2}$ Quik Column, an anion-exchange column system. The comparison was performed on all the 200 samples. The linear regression equation of $\mathrm{HbA}_{2}$ values, measured by anion exchange, against $\mathrm{HbA}_{2}$ values, measured by HPLC, was $\mathrm{y}=$ $0.337+0.984 \mathrm{x}$, with a correlation coefficient of 0.99 (fig 3 ). $\mathrm{HbA}_{2}$ results determined by HPLC gave excellent agreement with those obtained using the $\beta$-thal Quik Column. Both methods identified the same individuals with $\beta$-thalassaemia trait or $\mathrm{HbE}$ among the 200 cases screened, without any false negative or false positive results. In the
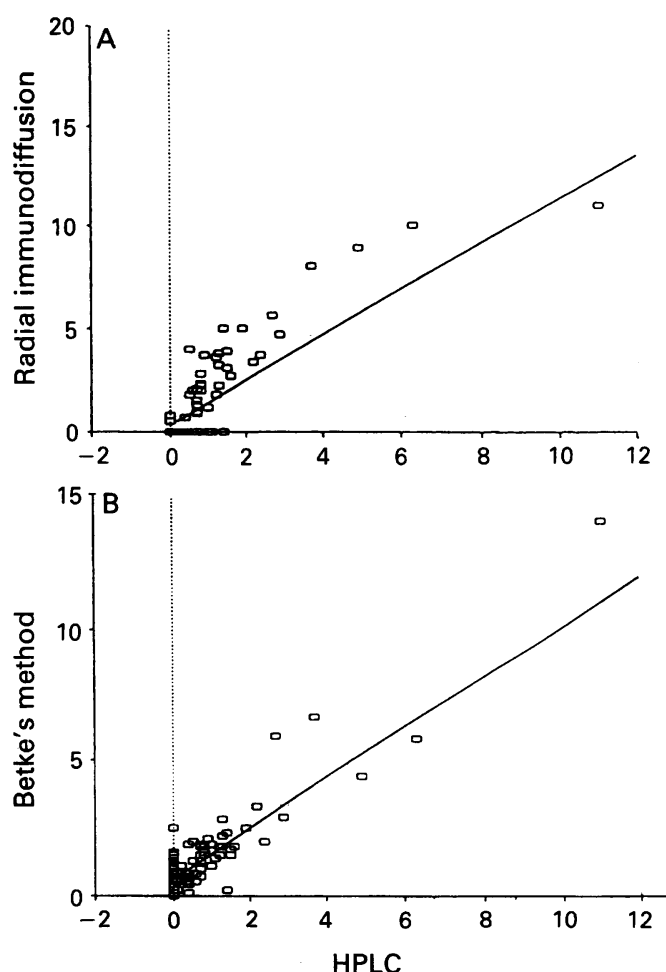

Figure 4 (A) Linear regression plot of HbF concentrations measured by RID against HbF concentrations measured by HPLC. Correlation coefficient $r=0.90 ; n=147$. (B) Linear regression plot of $\mathrm{HbF}$ concentrations measured by Betke's method against HbF concentrations measured by HPLC. Correlation coefficient $r=0.93 ; n=147$. 

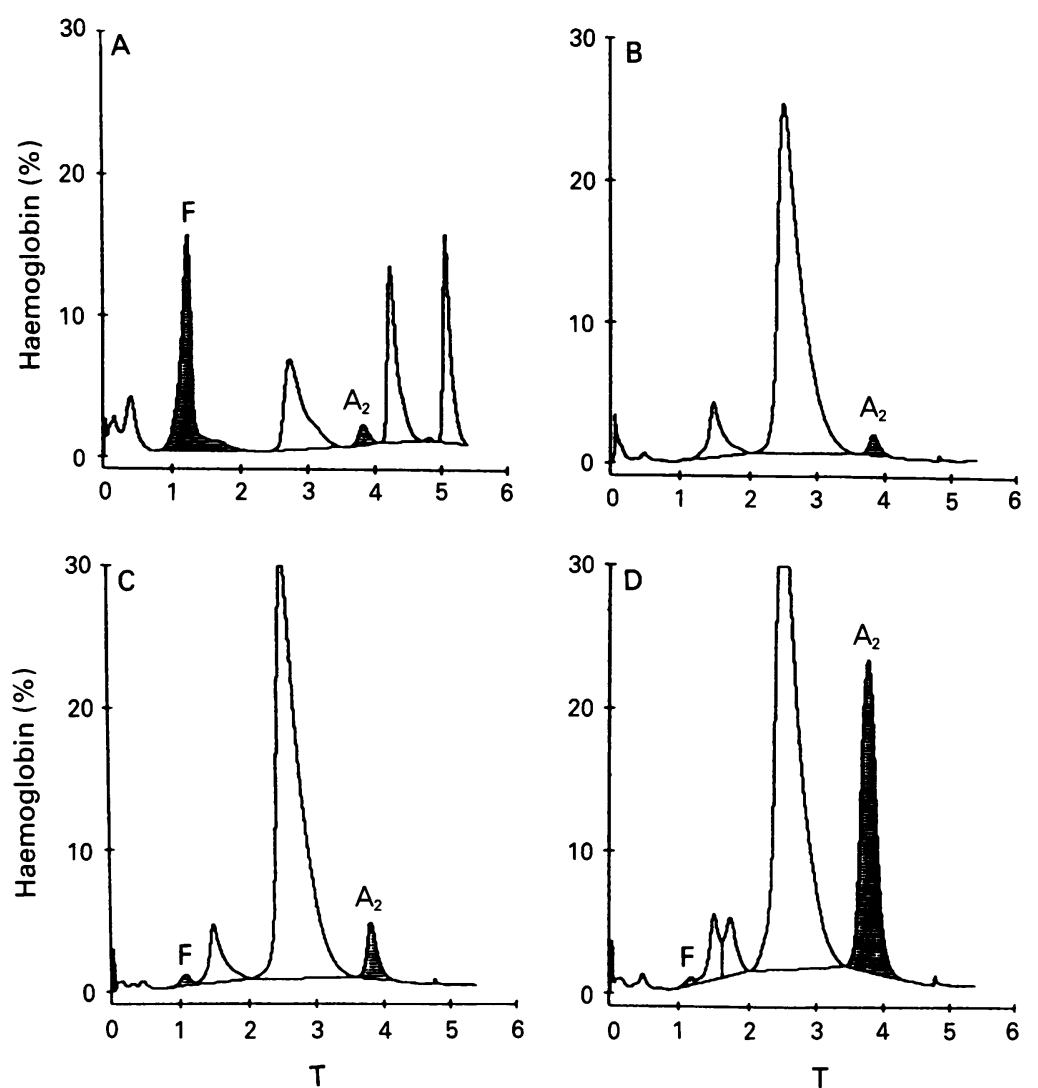

Figure 5 Graphical output of the VARIANT Hemoglobin Testing System. T = retention time in minutes. $\mathrm{HbF}$ and $\mathrm{HbA}_{2}$ appear as shaded peaks. (A) Control haemoglobin samples. Successive eluted peaks are haemoglobins $F, A, A, S$ and $C$. $H b F=27 \cdot 8 \%$, $H b A_{2}=2 \cdot 4 \%$. (B) Normal subject; $\mathrm{HbF}=0 \%, \mathrm{HbA}_{2}=2 \cdot 2 \%$. (C) $\beta$-thalassaemia trait; $\mathrm{HbF}=0.9 \%, \mathrm{HbA}_{2}=4.9 \%$. (D) Haemoglobin $\mathrm{E}$ trait; $\mathrm{HbF}=0.3 \%$, apparent $\mathrm{Hb} \mathrm{A}_{2}$ concentration $=23 \cdot 6 \%$.
$\mathrm{HbH}$ was not detected in any of the retention profiles from 27 subjects with $a$-thalassaemia trait, which all showed scanty erythrocyte $\mathrm{HbH}$ inclusions by staining.

Although the VARIANT could separate $\mathrm{HbC}$ from $\mathrm{HbA}_{2}$ (fig $5 \mathrm{~A}$ ), it could not distinguish between $\mathrm{HbE}$ and $\mathrm{HbA}_{2}$ (fig $5 \mathrm{D}$ ).

Small companion peaks probably due to glycosylated and degraded haemoglobins (Bio-rad Laboratories; unpublished data) were found to elute between the $\mathrm{HbF}$ and $\mathrm{HbA}_{2}$ peaks in most of the patient samples tested (figs 5B-5D).

\section{Discussion}

Currently, anion exchange column chromatography or radial immunodiffusion and alkaline denaturation are established methods for the determination of $\mathrm{HbA}_{2}$ or $\mathrm{HbF}$, respectively. ${ }^{23}$ The VARIANT Haemoglobin Testing system introduces cation-exchange HPLC for the estimation of $\mathrm{HbA}_{2}$ and $\mathrm{HbF}$ for routine thalassaemia screening. Linear regression analysis of $\mathrm{HbA}_{2}$ values measured by HPLC showed excellent correlation with values obtained by column anion exchange chromatography. For HbF, HPLC measurements also showed good correlation with values obtained using RID or Betke's method, although a better correlation was observed with the latter technique. The reference ranges obtained for $\mathrm{HbA}_{2}$ and $\mathrm{HbF}$ in this study agree with those of several previous investigators using HPLC. ${ }^{14} 1718$

An increase in the $\mathrm{HbA}_{2}$ in the range of $4-6 \%$ is specific for $\beta$-thalassaemia trait after the third month of life, ${ }^{14}$ and high $\mathrm{HbA}_{2}$ concentrations are a result of $\beta$-thalassaemia in almost all instances. ${ }^{19}$ Some individuals with $\beta$ thalassaemia trait, however, have normal indices, ${ }^{1419}$ so that in population surveys when the $\mathrm{HbA}_{2}$ is measured only in cases with a mean corpuscular volume below a certain cutoff value $(\leq 80 \mathrm{fl})$, such individuals may not be detected. Conversely, $\mathrm{HbA}_{2}$ concentrations may be normal in the rare "silent" $\beta$-thalassaemia trait with a normal $\mathrm{HbA}_{2},{ }^{1}$ so that an increased $\mathrm{HbA}_{2}$ cannot be used as the sole discriminant for $\beta$-thalassaemia.

A low $\mathrm{HbA}_{2}$ concentration may be seen in $\mathrm{HbH}$ disease, ${ }^{1}$ as illustrated by the three cases of $\mathrm{HbH}$ disease in our study.

Both electrophoretic or conventional chromatographic methods are unable to differentiated $\mathrm{HbA}_{2}$ from haemoglobin variants such $\mathrm{HbE}$ or $\mathrm{HbC}$, that contain similar charge differences. ${ }^{19}$ HPLC, however, has been reported to be capable of resolving $\mathrm{HbC},{ }^{11-14}$ $\mathrm{O}-\mathrm{Arab},{ }^{11}$ and Agenogi ${ }^{14}$ from $\mathrm{HbA}_{2}$. The VARIANT resolved haemoglobins $A, A_{2}, F$, $S$, and was able to differentiate $\mathrm{HbC}$ from $\mathrm{HbA}_{2}$. It could not distinguish, however, $\mathrm{HbE}$ from $\mathrm{HbA}_{2}$ (see below) or consistently resolve $\mathrm{HbH}$. A simple and accurate method for $\mathrm{HbH}$ and $\mathrm{Hb}$ Barts estimation would be highly effective for $a$-thalassaemia screening in South-East Asian populations. ${ }^{4}$

Of the haemoglobin variants which comigrate with $\mathrm{HbA}_{2}$, it is $\mathrm{HbE}$ principally which 5D). It did not, however, consistently distinguish $\mathrm{HbH}$, which elutes before the start of the integration program (at 1 minute), in three cases of $\mathrm{HbH}$ disease (not shown). 
interferes with $\mathrm{HbA}_{2}$ estimation in South-East Asian populations. Its clinical importance resides in the fact that while heterozygous or homozygous $\mathrm{HbE}$ do not cause clinically important anaemia, compound heterozygotes for $\mathrm{HbE}$ and $\beta$-thalassaemia $\left(\beta^{\mathbb{E} / \beta^{\text {thal }}}\right)$ may express a phenotype indistinguishable from homozygous $\beta$-thalassaemia. ${ }^{127}$ In practice, $\mathrm{HbE}$ carriers may be readily distinguished from $\beta$-thalassaemia trait by the apparent concentration of $\mathrm{HbA}_{2}$. The highest concentration of $\mathrm{HbA}_{2}$ in a large population of $\beta$ thalassaemia carriers of diverse ethnic backgrounds is reported to be $6 \cdot 8 \%$, but $\mathrm{HbA}_{2}$ concentrations in some 5 , $\beta$-gene deletion thalassaemias may range from $7-12 \% .{ }^{19} \mathrm{HbE}$ concentrations in heterozygotes are typically in excess of $20 \% .^{27}$ Therefore, $\mathrm{HbA}_{2}$ concentrations in excess of perhaps $10 \%$ should suggest coelution of an abnormal haemoglobin such as $\mathrm{HbE}$. In our study all samples with apparently high $\mathrm{HbA}_{2}$ concentrations $(17 \%$ to $30 \%$ ) were consistent with heterozygous $\mathrm{HbE}$ by other variables. Additional family or molecular studies are sometimes necessary to confirm $\beta^{\mathbb{E} / \beta^{\text {thal }}}$ or $\beta^{\mathbb{E}} / \alpha^{\text {thal }}$ compound heterozygosity. ${ }^{12}$ In this study all cases of $\beta$ thalassaemia trait or presumptive heterozygous $\mathrm{HbE}$ could be readily identified using the $\mathrm{HbA}_{2}$ concentration determined by HPLC as the sole discriminant.

The $\mathrm{HbF}$ concentration was increased $(\geq 0.8 \%)$ in $46 \%$ of the cases of $\beta$ thalassaemia trait in this study, in agreement with previous findings. ${ }^{14}$ Although the $\mathrm{HbF}$ concentration is not a useful discriminant for $\beta$-thalassaemia trait, an increased $\mathrm{HbF}$ concentration may be useful for the detection of homozygous $\beta$-thalassaemia variants, $\delta \beta$ thalassaemia, hereditary persistence of fetal haemoglobin or $\beta^{\mathbb{E} / \beta^{\text {thal }}} .12419$

Important features of the VARIANT Hemoglobin Testing system are that it requires only $5 \mu \mathrm{l}$ of whole blood, and that the procedure is fully automated, and provides a retention profile in only 6.5 minutes. These features are considerable advantages in population screening programmes for thalassaemia and other haemoglobin disorders. We estimate the cost per test to be comparable with that of existing methods for laboratories with large work volumes.

Our results show that HPLC is a reliable and technically easy method which can give accurate quantitation of haemoglobin fractions $\mathrm{HbA}_{2}$ and $\mathrm{HbF}$. The saving of labour and rapid turnround time are added advantages. Our study supports the notion that the efficiency of HPLC may be exploited in screening on a large scale for $\beta$-thalassaemia and $\mathrm{HbE}$ in South-East Asian populations.
The $\mathrm{HbA}_{2}$ and $\mathrm{HbF}$ concentrations obtained, however should be interpreted together with other variables such as erythrocyte indices, and iron studies, or family studies in some individuals. Furthermore, because of the large number of known haemoglobin variants (almost 400$)^{2}$ screening data would need to be supplemented in individual cases by methods such as isoelectric focusing, haemoglobin chain separation studies, or haemoglobin gene analysis.

We are grateful to Microstate Separations and the Bio-Rad Diagnostics Group for the generous loan of the VARIANT Haemoglobin Testing System together with reagents and technical assistance, and to Ms Jane Teo for typing the manuscript.

1 Weatherall DJ, Clegg JB. The thalassaemia syndromes. 3rd edn. Oxford: Blackwell Scientific Publications, 1981.

2 Bunn HF, Forget BG. Hemoglobin: molecular, genetic and clinical aspects. Philadelphia: WB Saunders, 1986

3 Wood WG. Haemoglobin analysis. In: Weatherall DJ, ed. The thalassaemias. Edinburgh: Churchill Livingstone, 1983:31-53.

4 Wasi P. Population screening. In: Weatherall DJ, ed. The thalassaemias. Edinburgh: Churchill Livingstone, 1983: 134-44

5 Kazazian HH Jr. The thalassaemia syndromes: Molecular basis and prenatal diagnosis in 1990. Semin Hematol 1990;27:209-28.

6 Na-Nakorn $S$, Wasi $P$. The distribution of haemoglobin E: Haemoglobin E triangle in South east Asia. $₹ \mathrm{Med}$ Assoc Thai 1978;61:65-71.

7 Anderson HM, Ranney HM. SouthEast Asian Immigrants: The new thalassaemias in America. Semin Hematol 1990;27:239-46.

8 International Committee for Standardization in Haematology. Recommendations for Selected Methods for Quantitative Estimation of $\mathrm{HbA}_{2}$ and for $\mathrm{HbA}$ Reference Preparation. Br ₹ Haematol 1978;38:573-8.

9 Huisman THJ, Jonkis JHP. The hemoglobinopathies. Techniques of identification. New York: Marcel Dekker, 1977:124-8.

10 Huisman THI, Gardiner MB, Wilson JB, Experiences with the quantitation of haemoglobin types by high with the quantitation of haemoglobin types by high performance liquid

11 Wilson JB, Headlee ME, Huisman THJ. A new highperformance liquid chromatographic procedure for the separation and quantitation of various hemoglobin variants in adults and newborn babies. $f$ Lab Clin Med $1983 ; 102: 174-85$.

12 Kutlar A, Kutlar F, Wilson JB, Headlee MG, Huisman THJ. Quantitation of hemoglobin components by high performance cation-exchange liquid chromatography: performance cation-exchange liquid chromatography: its use in diagnosis and in the assessment of cellular distribution of 17 .

13 Rogers BB, Wessels RA, Ou CN, Buffone GJ. Highperformance liquid chromatography in the diagnosis of hemoglobinopathie

14 Samperi P, Mancuso GR, Dibenedetto SP, Di Cataldo A, Ragusa $R$, Schiliro $G$. High performance liquid chromatography (HPLC): a simple method to quantify HbC, O-Arab, Agenogi and F. Clin Lab Haematol 1990; 13:169-75.

15 Betke K, Marthi HR, Schilcht I. Estimation of small percentages of foetal hemoglobin. Nature 1959;184: $1877-80$.

16 Lehmann H, Huntsman RG. Man's hemoglobins. Amsterdam: Holland, 1974

17 Kutlar A, Kutlar F, Gu L, Maysan SM, Huisman THJ. Fetal hemoglobin in normal adults and $\beta$-thalassemia Fetal hemoglobin in normal adults and $\beta$ -
heterozygotes. Hum Genet 1990;85:106-10.

18 Deacon-Smith $R$, Lord I. Haemoglobin $A_{2}$ measurement using high performance liquid chromatography. Med using high performance

19 Steinberg MH, Adams III JG. Hemoglobin $\mathrm{A}_{2}$ : Origin, evolution and aftermath. Blood. 1991;78:2165-77. 